\title{
High-resolution Electrical Resistivity Tomography monitoring of a tracer test in a confined aquifer
}

P.B. Wilkinson*, P.I. Meldrum, O. Kuras, J.E. Chambers, S.J. Holyoake, R.D. Ogilvy

British Geological Survey, Kingsley Dunham Centre, Keyworth, Nottingham, NG12 5GG, United Kingdom

* Corresponding author. Tel.: +44-115-936 3086; Fax: +44-115-936 3261; E-mail: pbw@bgs.ac.uk 


\begin{abstract}
A permanent geoelectrical subsurface imaging system has been installed at a contaminated land site to monitor changes in groundwater quality after the completion of a remediation programme. Since the resistivities of earth materials are sensitive to the presence of contaminants and their break-down products, 4-dimensional resistivity imaging can act as a surrogate monitoring technology for tracking and visualising changes in contaminant concentrations at much higher spatial and temporal resolution than manual intrusive investigations. The test site, a municipal car-park built on a former gas-works, had been polluted by a range of polycyclic aromatic hydrocarbons and dissolved phase contaminants. It was designated statutory contaminated land under Part IIA of the UK Environmental Protection Act due to the risk of polluting an underlying minor aquifer. Resistivity monitoring zones were established on the boundaries of the site by installing vertical electrode arrays in purpose-drilled boreholes. After a year of monitoring data had been collected, a tracer test was performed to investigate groundwater flow velocity and to demonstrate rapid volumetric monitoring of natural attenuation processes. A saline tracer was injected into the confined aquifer, and its motion and evolution were visualised directly in high-resolution tomographic images in near real-time. Breakthrough curves were calculated from independent resistivity measurements, and the estimated seepage velocities from the monitoring images and the breakthrough curves were found to be in good agreement with each other and with estimates based on the piezometric gradient and assumed material parameters.
\end{abstract}

Keywords: $\quad$ Electrical Resistivity Tomography; Timelapse; 3D; 4D; Environmental Monitoring; Tracer; Natural Attenuation 


\section{Introduction}

The use of Electrical Resistivity Tomography (ERT) to study near-surface hydrogeological characteristics and processes over a range of spatial and temporal scales has been an area of active research for more than a decade. As resistivity depends on properties such as saturation, solute concentration and temperature, timelapse ERT can be used to monitor natural and anthropogenic processes that cause changes in these properties, such as infiltration (Daily et al., 1992; Looms et al., 2008), saline intrusion (Slater and Sandberg, 2000; Ogilvy et al., 2007; 2008), leachate recirculation (Guerin et al., 2004), and contaminated land remediation (Daily and Ramirez, 1995; LaBrecque et al., 1996; Slater and Binley, 2003; Halihan et al., 2005, Wilkinson et al., 2008).

Timelapse ERT provides dynamic volumetric information while being either noninvasive (when using surface electrodes) or minimally invasive (with borehole electrodes). Therefore this method is well suited to monitoring tracer tests as part of hydrogeological site investigations. It typically gives much higher spatial resolution than geochemical sampling via monitoring boreholes and is therefore better able to capture the complex evolution of a tracer plume. This is particularly advantageous when monitoring natural flow, or forced flow in heterogeneous and/or anisotropic formations (Kemna et al., 2002; Sandberg et al., 2002; Cassiani et al., 2006; Vanderborght et al., 2005). Typically, surface ERT can monitor more extensive regions than cross-borehole ERT, but because its resolution decreases markedly with depth it tends to be used only for shallow hydrogeological systems (Cassiani et al., 2006; Nimmer et al., 2007). The most common approach is to monitor cross-hole resistivity data and use $2 \mathrm{D}$ inversion algorithms to generate images in the borehole planes (e.g. Daily and Ramirez; 1995; LaBrecque et al., 1996; Slater et al., 1997; Sandberg et al., 2002; Kemna et al., 2002; Deiana et al., 2007; Looms et al., 2008). $2 \mathrm{D}$ inversion is rapid, permitting monitoring on timescales of tens of minutes to a few hours, but provides information only in the plane between the boreholes and is prone to artefacts caused by off-plane 3D features (Nimmer et al., 2008). By contrast 3D inversion produces volumetric images, fully reconstructing the 3D nature of the tracer plume, albeit with decreasing resolution at greater distances from the boreholes. This method has been used to monitor tracer tests on timescales of several hours to a few days, typically using fewer than 10 boreholes, each with some $10-20$ electrodes (Daily and Ramirez, 2000; Binley et al., 2002; Singha and Gorelick, 2005; Oldenborger et al., 2007a; Kuras et al., 2009). In many cases, quantitative estimates can be made of seepage velocities (Sandberg et al., 2002), spatial moments (Binley et al., 2002; Singha and Gorelick, 2005; Looms et al., 2008), hydraulic conductivity (Binley et al., 2002), and tracer mass and concentration (Singha and Gorelick, 2006; Oldenborger et al., 2007a).

In this paper, we present the results of a high spatial and temporal resolution 3D timelapse monitoring study of a saline tracer test. The electrode network comprised 14 boreholes, each with 16 electrodes, covering an area of $\sim 40 \mathrm{~m}^{2}$. Tomographic images were obtained every 4 hours from a remotely-controlled automated geoelectrical monitoring system. The test was undertaken at a former gasworks site that had recently undergone remediation, which had been monitored for over a year using a combination of geoelectrical imaging and conventional groundwater sampling to validate its success. The aim of the tracer test was to determine the direction and speed of the groundwater flow and to demonstrate the ability to monitor natural 
attenuation processes such as dilution and dispersion in near real-time using automated ERT.

\section{Context}

The CLARET (Contaminated Land: Assessment of Remediation by Electrical Tomography) project was undertaken by a public/private consortium comprising a research institution, two companies, and a local government authority. The aim of the project was to develop automated 4D geoelectrical imaging as a minimally invasive tool to monitor contaminated land and validate remediation processes. Figure 1 illustrates the general monitoring concept. Electrodes are installed at a site where a receptor (e.g. a controlled water body) is at risk of contamination. Monitoring of the geoelectrical properties of the site takes place either automatically in near real-time, or on-demand, with data being transmitted via one of several possible communication channels to the office for automated processing and inversion. This process generates volumetric time-lapse images of the resistivity of the subsurface, which is dependent on the geology, the groundwater chemistry, and the presence of bulk contaminants and their breakdown products (Shevnin et al., 2006). Since the geology is static, monitoring changes in the resistivity images over time highlights temporal variations in contamination or groundwater quality associated with remediation. A key advantage of this approach is that the volumetric images can provide information to help interpolate between point samples and give extra assurance that contamination has not been missed.

The CLARET research site was located in Stamford, UK, on the site of a former gasworks that has been in use as a municipal car park since 1972 (Fig. 2a). The land, known as the Wharf Road car park, was declared as being statutorily contaminated in February 2005 under Part IIA of the UK Environmental Protection Act 1990. Site investigations found that the highest levels of contamination were in the southern half of the site, and were generally associated with former processing and refining areas. Several significant linkages were identified between the controlled waters of an underlying minor aquifer and a range of pollutants including PAHs (polycyclic aromatic hydrocarbons), BTEX (benzene, toluene, ethylbenzene, xylene) compounds, petrol range organics, ammoniacal nitrogen, sulphates and cyanides.

Remedial works began in April 2007, with the grossly contaminated hotspots being excavated and removed to licensed landfill sites. Other excavated soils were treated by ex-situ bioremediation to enable their re-use on site. The excavations were validated by analysing soil samples taken from the sides and bases to demonstrate that contaminant concentrations were below the target values agreed with the local government authority and the Environment Agency. The excavations were infilled with clean processed granular materials obtained from re-grading the car park.

\section{Electrode network and ALERT system}

The electrode network was installed after the excavations had been infilled and before the car park surface was reinstated. The network was arranged to cover the southeastern corner of the boundaries with the River Welland to the south and privately owned land to the east (Figs. 2a \& b). Each of the 14 vertical electrode arrays was installed during a 3-day period in a purpose-drilled borehole and each can be accessed via an inspection cover. The arrays each had 16 electrodes spaced at $0.5 \mathrm{~m}$ depth intervals, and were connected via purpose-built subsurface conduits to a system 
enclosure just beyond the southern boundary of the site. The installation was undertaken in accordance with Environment Agency and Construction (Design \& Management) 2007 regulations. The installed system and electrode network had little visual impact on the site (Fig. 2c), and no impact on its use as a car park.

Before installation, the noise characteristics were measured of four prototype arrays comprising stainless steel, naval brass, phosphor bronze or lead electrodes. Each array was placed in an existing groundwater monitoring borehole on the site and a set of dipole-dipole measurements were made with reciprocals. It was found that the phosphor bronze electrodes exhibited the lowest levels of reciprocal error. The electrodes for the permanent arrays were therefore constructed from $5 \mathrm{~mm}$ diameter phosphor bronze rods, each with an exposed length of $4 \mathrm{~cm}$ (Fig. 3a). Each array was installed in a $100 \mathrm{~mm}$ diameter hole drilled using the sonic percussion drilling method. The electrode array was located inside the drill stem and pushed to depth. A plastic lost-point at the end of the drill stem was then released to leave the array in position and allow the stem to be withdrawn over the installed array. Each array was mounted onto the outside of eight $1 \mathrm{~m}$ bentonite sleeve sections (Fig. 3b). After installation, swelling of the bentonite sleeves caused the borehole to close, ensuring good electrical contact with the surrounding formation while simultaneously preventing the creation of new pollution pathways. A single $\mathrm{Pb} / \mathrm{PbCl}_{2}$ non-polarising electrode was also installed at the top of each of the arrays to monitor self-potential.

The resistivity distribution of the subsurface in the vicinity of the electrode network was monitored on a regular and frequent basis during the project by a British Geological Survey (BGS) proprietary geoelectrical imaging system. This system, known as ALERT (Automated time-Lapse Electrical Resistivity Tomography), enables near real-time autonomous in-situ monitoring of electrical resistivity, induced polarisation and self-potential data. It uses wireless telemetry (e.g: GSM/3G, internet, GPRS, or satellite) to communicate with a database management system at the office, which controls the storage, inversion and delivery of the data and resulting tomographic images. Once installed, no manual intervention is required; data is transmitted automatically according to a pre-programmed schedule and specific survey parameters, both of which may be modified remotely as conditions change. The ALERT instrument is a single unit, contained in a sealed environmental casing (Fig. 2c inset). Connection of external sensors to the instrument is made via high specification water-proof connectors mounted on the side of the case. The system is powered by 12 or $24 \mathrm{~V}$ batteries, with mains, solar or wind turbine charging options. It supports 10-channel simultaneous potential difference measurements, and openended expansion of the number of attached electrodes (in multiples of 32). Specifically, at the test site 238 of a total 288 available electrode addresses were in use (224 resistivity electrodes and 14 self-potential electrodes). The batteries were charged by mains power, and communications were provided via a $3 \mathrm{G}$ wireless cellular router.

\section{Data acquisition}

To monitor subsurface changes associated with the site remediation, resistivity data were collected between pairs of adjacent boreholes ("panels") as shown in Fig. 4a. The measurement scheme comprised many sets of four-electrode measurements, in which the current flow and potential measurements are crosshole. In general, these provide better signal-to-noise characteristics and greater image resolution than configurations with in-hole current flow and potential measurements (Bing and 
Greenhalgh, 2000; Wilkinson et al., 2006; 2008). To provide sufficient image resolution in crosshole ERT, it is important that the aspect ratio of the panel (borehole spacing / depth) is < 0.75 (LaBrecque et al., 1996). In our case, each panel had an aspect ratio $<0.5$.

Since the system is capable of multichannel data acquisition, many potential measurements were made for each pair of current electrodes. The measurement sets were classified into two types: forward and reciprocal. For the forward measurements, a pair of current electrodes was selected with a vertical offset of $s$ electrode spacings (solid lines in Fig. 4a). The first potential difference was measured on the electrodes immediately above the current bipole, followed by successive alternating pairs going up the boreholes (dotted lines in Fig. 4a). To cover the whole panel, this geometry was repeated to the top of the boreholes. After this, equivalent reciprocal measurements were made with the current and potential bipoles interchanged (so that the potential differences are now measured beneath the current electrodes). The purpose of making reciprocal measurements is that, in the absence of systematic and random error, equivalent forward and reciprocal electrode configurations should yield the same resistivity value (Parasnis, 1988; Zhou and Dahlin, 2003). Any difference between the two gives a reliable indicator of the error in the measurement.

To cover the monitoring region, the single panel measurement scheme was repeated on each of the 31 panels shown by dashed lines in Fig. 4b. During the postremediation monitoring phase of the project, forward and reciprocal data were measured on each panel for vertical offsets of $s=0, \pm 3, \pm 6, \pm 9, \pm 12$. For the rapid monitoring required during the tracer test, only $s=0$ was used. Reciprocal data were recorded to assess data quality immediately prior to the test, but during the tracer monitoring only forward measurements were made. The changes were made to reduce data acquisition and battery recharge time from 2 days per data set during remediation monitoring to 4 hours per set during the tracer test. The effect of this reduction in data density on the resulting inverted images is discussed below.

\section{Data quality}

The contact resistances of the electrodes were checked to ensure their suitability to inject current and measure potential differences. The large majority were in excellent contact with the ground, having contact resistances of $200-300 \Omega \mathrm{m}$. Only four electrodes were making either poor or no contact. These were on array 1 at $1.0 \mathrm{~m}$ depth, array 4 at $3.5 \mathrm{~m}$ depth, array 5 at $1.5 \mathrm{~m}$ depth, and array 8 at $1.5 \mathrm{~m}$ depth. No measurements were made involving these electrodes.

Data quality was assessed in terms of reciprocal error before the tracer test began. The measured resistivity value $\rho$ was taken to be the mean of the forward measurement $\left(\rho_{\mathrm{f}}\right)$ and its reciprocal $\left(\rho_{\mathrm{r}}\right)$, i.e. $\rho=\left(\rho_{\mathrm{f}}-\rho_{\mathrm{r}}\right) / 2$. Since the standard error of the mean of these two resistivity measurements is $\left|\rho_{\mathrm{f}}-\rho_{\mathrm{r}}\right| / 2$, the percentage error is given by

$$
100 \frac{\left|\rho_{\mathrm{f}}-\rho_{\mathrm{r}}\right|}{\left(\rho_{\mathrm{f}}+\rho_{\mathrm{r}}\right)},
$$

which is hereafter referred to as the reciprocal error. This was calculated for all $s=0$ measurements to assess the data quality for the whole set. The distribution of reciprocal errors is shown in Fig. 5. 98.7\% of the data had errors of $<0.3 \%$, and the maximum error recorded was only $2.7 \%$. These errors are extremely low, validating the electrode design, the material choice and installation method of the arrays. 


\section{Ground truth and baseline resistivity image}

Intrusive site investigations were undertaken in 2003 and 2006, and borehole cores were recovered in 2007 during the installation of electrode arrays 5, 8 and 9. The general lithological sequence observed at the site was made ground, overlying alluvial clays, river terrace sand and gravels, and clay bedrock. Before remediation, fissures in the clays provided a pathway for gasworks pollutants in the made ground to seep and leach into the river terrace deposits. After remediation, the made ground consisted of $2-3 \mathrm{~m}$ of bioremediated infill material. The site investigation logs indicated the occurrence of varying amounts of sands and gravel in the alluvial clays, whilst the array installation logs suggested that the alluvial deposits and river terrace sands and gravels are interbedded. At depths of $\sim 5 \mathrm{~m}$, the logs indicated a continuous deposit of sands and gravels, forming a minor aquifer of $0.5-1 \mathrm{~m}$ thickness. Underlying this are further layers of alluvium and river terrace deposits and clay bedrock, identified as Whitby Mudstone in the installation logs. The aquifer was assumed to be semiconfined by this underlying alluvium and bedrock.

A subsurface resistivity image obtained in September 2008 during post-remediation monitoring is shown in Figs. 6a $\&$ b. The data were inverted with the Res3DInv software using a finite difference method, the incomplete Gauss-Newton solver, an $L_{1}$ data constraint, and an $L_{2}$ model constraint weighted to emphasize horizontally layered structures. The data were subdivided into two overlapping rectangular blocks of panels for inversion, a southern block bounded by arrays 3, 4, 8 and 14 (see Fig. 4b) and an eastern block bounded by arrays 1, 4, 5 and 9. These blocks were discretised into cubic model cells of side length $0.25 \mathrm{~m}$. Fig. 6a shows a vertical slice through the southern block model along the line $y=2.375 \mathrm{~m}$. Similarly, Fig. $6 \mathrm{~b}$ shows a vertical slice through the eastern block model along $x=10.375 \mathrm{~m}$. Convergence was reached after 10 iterations, with mean absolute misfit errors of $3.1 \%$ and $2.8 \%$ respectively. In the images, the electrodes are shown as white rectangles, and a lithological $\log$ from array 8 is shown to the right of Fig. $6 \mathrm{~b}$ at the same depth scale.

The images exhibit alternating resistive and conductive horizontal layers that correlate well with the lithology above the base of the aquifer. The top $3 \mathrm{~m}$ of bioremediated, infilled ground are predominantly resistive, since they are less well compacted than the undisturbed ground beneath and therefore better drained. The Flandrian river alluvium, at depths of $\sim 3-5 \mathrm{~m}$ below ground level (bgl), has high clay content and hence is very conductive (although resistivities of $<3 \Omega \mathrm{m}$ are unusually low for clay, see below). Beneath this, at depths of $\sim 5-6 \mathrm{~m} \mathrm{bgl}$, is the minor aquifer consisting predominantly of sands and gravel. Electrical conduction in this layer is dominated by the groundwater, which is more resistive than the clay-rich alluvium. Beneath this, the correlation with the borehole logs is not as clear. The logs indicate further sands and gravels, above a layer of Whitby mudstone at depths of over $7 \mathrm{mbgl}$. The images indicate thin alternating resistive and conductive layers, possibly underlain by conductive bedrock at $\sim 8 \mathrm{~m}$ bgl. Two of these three resistive layers do not appear to be continuous, although their disappearance with increasing distance from the borehole electrodes is probably due to the associated decrease in image resolution with increasing distance (Kemna et al., 2002, Oldenborger et al., 2007b). It is possible that the lack of quantitative agreement between the logs and the images below $6 \mathrm{~m}$ bgl is due to slippage in the core barrel. This occurs when material in the core barrel shifts into void space produced by wash-out during sonic drilling, and it has been observed previously when using this method (Wilkinson et al., 2008). This type of drilling also compacts the ground in the vicinity of the borehole (Wilkinson et al., 2008), which 
may account for the strong borehole effects (the anomalous increases in resistivity that surround the borehole arrays). The raised resistivities near the boreholes may also account for lower-than-expected modelled resistivities for the surrounding alluvium, since resistivity contrasts near electrodes can cause "shadow" under- or over-shoots in adjacent regions (Dahlin and Zhou, 2004).

The piezometric level across the monitoring region was $\sim 2.2 \mathrm{~m}$ bgl. The levels were measured prior to the tracer test to assess the likely groundwater flow velocity and possibility of being able to monitor the test using crosshole ERT. The levels were measured in three groundwater monitoring wells (GMW3-5, Fig. 2b), which were screened only at depths of 4.3 - $5.5 \mathrm{~m}$ (GWM3), 5.0 - 6.0 m (GMW4) and $4.8-5.8 \mathrm{~m}$ (GMW5) to allow water to be drawn from the minor aquifer. Table 1 shows the piezometric levels below datum (ground level at GMW3). The surface topography was measured by theodolite and the depths to water by measuring tape.

Table 1

Piezometric levels

\begin{tabular}{llll}
\hline & GMW3 & GMW4 & GMW5 \\
\hline $\begin{array}{l}\text { Depth to water (m } \\
\text { below surface) }\end{array}$ & $2.20 \pm 0.01$ & $2.17 \pm 0.01$ & $2.23 \pm 0.01$ \\
$\begin{array}{l}\text { Surface topography } \\
\text { (m below datum) }\end{array}$ & 0 & $0.036 \pm 0.001$ & $0.054 \pm 0.001$ \\
$\begin{array}{l}\text { Piezometric level } \\
\text { (m below datum) }\end{array}$ & $2.20 \pm 0.01$ & $2.21 \pm 0.01$ & $2.28 \pm 0.01$ \\
\hline
\end{tabular}

The seepage velocity, $v$, is given in terms of the hydraulic conductivity, $K$, the effective porosity of the medium, $n$, and the head gradient, $I$, by

$v=\frac{K I}{n}$.

Coarse sands typically have hydraulic conductivities in the range $9 \times 10^{-7} \mathrm{~m} / \mathrm{s}<K<$ $6 \times 10^{-3} \mathrm{~m} / \mathrm{s}$, gravels have $3 \times 10^{-4} \mathrm{~m} / \mathrm{s}<K<3 \times 10^{-2} \mathrm{~m} / \mathrm{s}$, and typical porosities are $n \sim 0.3$ (Domenico and Schwartz, 1998). For the sand and gravel minor aquifer, it is reasonable to take the lower bound for gravel of $K=3 \times 10^{-4} \mathrm{~m} / \mathrm{s}$, which overlaps with the range for sand, to obtain an estimated seepage velocity of $v \sim 0.5 \mathrm{~m} /$ day between GMW4 and GMW5 (a distance of $14.0 \mathrm{~m}$ approximately in the $-x$ direction). By comparison the estimated velocity between GMW3 and GMW4, approximately in the $-y$ direction, is negligible ( $\sim 0.04 \mathrm{~m} /$ day $)$.

When monitoring dynamic processes using geoelectrical imaging there is an implicit assumption that the data are collected simultaneously. This assumption is reasonable if the characteristic time scales of the processes being monitored are significantly longer than the time required to collect the data. But if the processes are more rapid, so that significant changes can occur during data collection, then the resulting image can exhibit blurring and poor convergence with the measured data. The piezometric levels suggested that a tracer injected into the aquifer via GMW4 should flow almost directly towards GMW5, i.e. roughly antiparallel to the $x$-axis. Since the seepage velocity in this direction would be $\sim 0.5 \mathrm{~m} /$ day, the tracer would advance by $\sim 2$ 
model cells/day. To avoid temporal blurring a shorter monitoring period was required than was used in the post-remediation monitoring ( $\tau=2$ days). To reduce the period, only offsets of $s=0$ were used and reciprocal measurements were not made, giving a total of 4,689 apparent resistivity data for each image and reducing the measurement time to 1.7 hours. During this time, the tracer would have been expected to move by $<0.15$ model cells, significantly reducing any time-lapse blurring.

The total monitoring period was $\tau=4$ hours, which allowed time for the batteries to recharge and data to be inverted (the southern and eastern blocks took 25 and 18 minutes to invert respectively on a $2.4 \mathrm{GHz}$ dual core processor). The effects of reducing the data density can be seen in Figs. 6c and d, which show the baseline resistivity model for the tracer test that was obtained in October 2008, 18 hours prior to injection. The inversions converged after 7 iterations with mean absolute misfit errors of $1.9 \%$ for the both the southern and eastern blocks. There is a reduction in contrast in the baseline image in comparison with Figs. 6a and b, and the lack of nonzero vertical offsets appears to have reduced the lateral resolution. However, the layered structure of the image is still evident, and most of the lateral structure can still be discerned, suggesting that it should be possible to track the lateral position of the tracer front.

\section{Tracer test \& discussion}

A strong saline tracer (1000 litres, at a concentration of $40 \mathrm{~g} / \mathrm{l}$ ) was released into the aquifer via GMW4 to investigate the local groundwater flow velocity and to demonstrate rapid ERT monitoring of natural attenuation processes. A high concentration was used to give a good resistivity contrast. Density driven flow was assumed to be insignificant due to the underlying aquiclude. This investigation was beyond the original scope of the project, so there were no resources for repeated groundwater monitoring on the timescales required by the expected speed of the tracer, and no logger was available that could be installed in the groundwater monitoring wells. Instead, an extra set of resistivity data was taken during each 4-hour period. These comprised unit spaced Wenner apparent resistivity measurements taken on each individual electrode array. These were centred vertically on the aquifer and used the electrodes shown as white circles in Figs. $6 \mathrm{c}$ and d. Since these data were not used in the inversion, they could be used to plot independent breakthrough curves, the resistivity of which would decrease / increase as the local salinity of the aquifer increased / decreased (although the dependence would not be directly proportional, since the sensitivity distribution of the Wenner distribution extends beyond its upper and lower electrodes).

An environmental risk assessment was carried out to obtain permission to undertake the test from the Environment Agency and the local government authority. This indicated that the tracer should be injected at a moderate rate to minimise the risk of mobilising residual contamination by flushing. Therefore the tracer was released at a steady rate of $\sim 41 / \mathrm{min}$, taking just over 4 hours to release 10001 into the aquifer. Resistivity data were collected continuously from the time of the initial release. The Wenner apparent resistivity breakthrough curves are shown in Fig. 7. The curves are shown at distances in the $x$ direction of $0,2.5,5,7.5$ and $10.5 \mathrm{~m}$ (arrays 4, 5, 6, 7, and 14 respectively). The curve for array 2 (5 m separation in the $y$ direction) is also shown. For arrays 5, 6 and 14, there are small anomalous features in the breakthrough curves at $t \sim 24$ days after injection (indicated by small vertical arrows in Fig. 7). The source of these is not known 
, although they occur more strongly in other breakthrough curves that were not used (e.g. for array 8, the resistivity increase due to this feature has the same magnitude as the decrease due to the saline front and takes several days to decay, obscuring the resistivity minimum). Assuming the arrival time is shown by the arrowed resistivity minima, the mean tracer velocity is $v=0.45 \pm 0.06 \mathrm{~m} /$ day (see Table 2 ), which is in good agreement with the value estimated from the piezometric levels.

Table 2

Breakthrough curve tracer speeds

\begin{tabular}{lll}
\hline Distance from GMW4 (m) & Apparent resistivity minimum (days) & Speed (m/day) \\
\hline 3.24 & 5.5 & 0.59 \\
\hline 5.55 & 17.5 & 0.32 \\
\hline 7.95 & 18 & 0.44 \\
\hline 11.34 & 25.5 & 0.44 \\
\hline
\end{tabular}

The spatial distribution of the saline tracer can be seen clearly in the results of the ERT monitoring, which are shown in Fig. 8. Inverse models were generated from the monitoring data every four hours although, for the sake of conciseness, only representative images are displayed. While not obvious from this limited number of images, it is worth stressing that the evolution of the conductive region is smooth and continuous at the four-hour timescale. Each image shown in Fig. 8 was generated from the data set taken between 18:00 and 20:00 hours on the indicated day. For day 0 , this was 2 hours after the end of the tracer release. Due to the low levels of noise, the inversions were performed without time-lapse constraints and directly on separate data sets, rather than on differences between subsequent sets. In these circumstances, use of the background image as a starting model is not necessary (Miller et al., 2008). The mean absolute misfit errors for the models are all in the range $1.8 \%-1.9 \%$. The images are displayed normalised to the baseline model shown in Fig. 6c, since this reduces the strong borehole effects that are clearly visible in the baseline model (Slater et al., 2000; Descloitres et al., 2008). Due to the normalisation, regions that have become more conductive are shown as resistivity ratios $<1$. Only the southern block is displayed, since along the eastern block the tracer migration is observed to stop at $y=3.5 \mathrm{~m}$. The upper (horizontal) slices are at a depth of $5.375 \mathrm{~m} \mathrm{bgl}$, the lower (vertical) slices are at $y=1.375 \mathrm{~m}$.

The ERT images show the appearance and evolution of a conductive region between depths of $\sim 5-6 \mathrm{~m}$ bgl. The extent and intensity of this conductive region can be seen to vary considerably on the scale of several days. Only small changes in resistivity occurred at these depths over timescales of several months during post-remediation monitoring. Hence, it is reasonable to assume that any increases in conductivity are caused by increases in salinity due to the presence of the tracer. Therefore the changes in the images allow the distribution and density of the tracer to be visualised directly in 4D. They indicate that the tracer is predominantly localised in a horizontal aquifer that is reasonably uniform and approximately $1 \mathrm{~m}$ thick throughout the model space. The absence of conductivity increases above $5 \mathrm{mbgl}$ implies that there is little upwards migration of the tracer through fissures in the clay, and that the aquifer is reasonably well confined. There is some evidence that at $t=0$ a fraction of the tracer 
escaped from the injection borehole, suggesting that either the base or the sides of GMW4 are not perfectly sealed. By contrast, there appear to be no losses from the electrode array boreholes, which gives confidence that no pollution pathways were created during the array installations.

The changes in the extent of the conductive region suggest that the majority of the tracer was carried along the piezometric gradient in the $-x$ direction. The tracer speed can be estimated from the models by finding the time of minimum resistivity at the points marked by light blue crosses in Fig. 8. The resistivities were calculated as the average of all model cells immediately adjacent to each cross. Using this method the mean tracer speed was found to be $v=0.49 \pm 0.07 \mathrm{~m} /$ day (see Table 3), in good agreement with the estimate derived from the Wenner breakthrough curves. There is also evidence that there may be some tracer movement along the $y$ axis. Initially motion in this direction seems to have been dominated by dispersion. But comparison of the horizontal slices in Figs. 8d, e and $\mathrm{f}$ suggests that the tracer has since begun to move towards $-y$, indicating a small seepage velocity component in this direction.

Table 3

Model resistivity tracer speeds

\begin{tabular}{lll}
\hline Distance from GMW4 $(\mathrm{m})$ & Model resistivity minimum (days) & Speed $(\mathrm{m} /$ day $)$ \\
\hline 3.37 & 5 & 0.67 \\
5.64 & 16 & 0.35 \\
8.09 & 19 & 0.43 \\
11.20 & 23 & 0.49 \\
\hline
\end{tabular}

In addition to the large resistivity decreases observed in the aquifer layer, there are localised increases in resistivity of much lower magnitude in the made ground at depths of $\sim 1-2 \mathrm{~m}$. Similar changes in the made ground resistivity were observed during post-remediation monitoring, and were found to be strongly anticorrelated with the average air temperature over the previous 7 days. A tentative explanation for this effect is that increases in pore water resistivity in the made ground are caused by decreases in the received solar radiation, since the black tarmac surface above the made ground has a low albedo (Thompson, 1998).

\section{Conclusions}

The CLARET project has provided useful experience for the geoelectrical monitoring of contaminated land and remediation processes. It has shown that an electrode network can be installed in parallel with remedial works and in accordance with site and environmental regulations. The installation method was demonstrated to produce good electrical contact with the ground and excellent data quality. The ERT images generated from the data were generally in good agreement with the site lithology derived from core logging, providing useful complementary information where there was inconsistency in the recovered depths to interfaces.

The capabilities of geoelectrical monitoring were demonstrated by a saline tracer test. Using measurement sequences designed for rapid data acquisition, the volumetric images permitted the evolution of the tracer to be visualised directly throughout the 
entire monitoring volume in near real-time. Apparent resistivity breakthrough curves were measured independently of the imaging data on each electrode array. Quantitative estimates of seepage velocity derived from the images and the breakthrough curves were found to be in good agreement, and also agreed with estimates based on measured piezometric gradients and assumed hydrogeological parameters.

The tracer test has demonstrated that contaminants affecting the electrical resistivity of the subsurface can be tracked and monitored at field-scale in near real-time, on time scales of hours upwards. By enabling the direct observation of dispersion and dilution processes, this test has shown that geoelectrical monitoring of remediation is directly applicable to sites where remediation is being undertaken by monitored natural attenuation. However, there is no reason why the concept should not be equally applicable to most other in-situ remediation techniques operating on similar time-scales. In combination with calibration from intrusive sampling and resistivityconcentration relations that can be corrected for variable image resolution (Singha and Gorelick, 2006), time-lapse ERT has the potential to provide direct quantitative volumetric imaging of remediation processes.

\section{Acknowledgements}

This paper is published with the permission of the Executive Director of the British Geological Survey (NERC). The research was funded by a grant from the Technology Strategy Board (www.innovateuk.org; project TP/5/CON/6/I/H0048B) and contributions from a consortium partnership comprising VHE Construction Plc, Interkonsult Ltd and South Kesteven District Council. We are grateful to Dr R.A. White of BGS for undertaking the environmental risk assessment for the tracer test. We also thank the editor Prof. Alan Green and two anonymous reviewers for their helpful comments on our original manuscript.

\section{References}

Bing, Z., Greenhalgh, S.A., 2000. Cross-hole resistivity tomography using different electrode configurations. Geophysical Prospecting 48, 887-912.

Binley, A., Cassiani, G., Middleton, R., Winship, P., 2002. Vadose zone flow model parameterisation using cross-borehole radar and resistivity imaging. Journal of Hydrology 267, 147-159.

Cassiani, G., Bruno, V., Villa, A., Fusi, N., Binley, A. M., 2006. A saline trace test monitored via time-lapse surface electrical resistivity tomography. Journal of Applied Geophysics 59, 244-259.

Dahlin, T., Zhou, B., 2004. A numerical comparison of 2D resistivity imaging with 10 electrode arrays. Geophysical Prospecting 52, 379-398.

Daily, W., Ramirez, A., Labrecque, D., Nitao, J., 1992. Electrical-Resistivity Tomography of Vadose Water-Movement. Water Resources Research 28, 1429-1442.

Daily, W., Ramirez, A., 1995. Electrical resistance tomography during in-situ trichloroethylene remediation at the Savannah River Site. Journal of Applied Geophysics 33, 239- 249.

Daily, W., Ramirez, A., 2000. Electrical imaging of engineered hydraulic barriers. Geophysics 65, 83-94. 
Deiana, R., Cassiani, G., Kemna, A., Villa, A., Bruno, V., Bagliani, A., 2007. An experiment of non-invasive characterization of the vadose zone via water injection and cross-hole time-lapse geophysical monitoring. Near Surface Geophysics 5, 183194.

Descloitres, M., Ribolzi, O., Le Troquer, Y., Thiébaux, J.P., 2008. Study of water tension differences in heterogeneous sandy soils using surface ERT. Journal of Applied Geophysics 64, 83-98.

Domenico, P.A., Schwartz, F.W., 1998. Physical and Chemical Hydrogeology, John Wiley \& Sons, 506pp.

Guerin, R., Munoz, M.L., Aran, C., Laperrelle, C., Hidra, M., Drouart, E., Grellier, S., 2004. Leachate recirculation: moisture content assessment by means of a geophysical technique. Waste Management 24, 785-794.

Halihan, T., Paxton, S., Graham, I., Fenstemakerb, T., Rileya, M., 2005. Postremediation evaluation of a LNAPL site using electrical resistivity imaging. Journal of Environmental Monitoring 7, 283-287.

Kemna, A., Vanderborght, J., Kulessa, B., Vereecken, H., 2002. Imaging and characterisation of subsurface solute transport using electrical resistivity tomography (ERT) and equivalent transport models. Journal of Hydrology 267, 125-146.

Kuras, O., Pritchard, J., Meldrum, P.I., Chambers, J.E., Wilkinson, P.B., Ogilvy, R.D., Wealthall G.P., 2009. Monitoring hydraulic processes with Automated timeLapse Electrical Resistivity Tomography (ALERT). Comptes Rendus Geosciences Special Issue on Hydrogeophysics (in press).

LaBrecque, D.J., Ramirez, A.I., Daily, W.D., Binley, A.M., Schima, S.A., 1996. ERT monitoring of environmental remediation processes. Measurement Science and Technology 7, 375-383.

Looms, M.C., Jensen, K.H., Binley, A., Nielsen, L., 2008. Monitoring unsaturated flow and transport using cross-borehole geophysical methods. Vadose Zone Journal 7, 227-237.

Miller, C.R., Routh, P.S., Brosten, T.R., McNamare, J.P., 2008. Application of timelapse ERT imaging to watershed characterization. Geophysics 73, G7-G17.

Nimmer, R.E., Osiensky, J.L., Binley, A.M., Sprenke, K.F., Williams, B.C., 2007. Electrical resistivity imaging of conductive plume dilution in fractured rock. Hydrogeology Journal 5, 877-890.

Nimmer, R.E., Osiensky, J.L., Binley, A.M., Williams, B.C., 2008. Threedimensional effects causing artifacts in two-dimensional, cross-borehole, electrical imaging. Journal of Hydrology 359, 59-70.

Ogilvy, R.D., Kuras, O., Meldrum, P.I., Wilkinson, P.B., Gisbert, J., Jorreto, S., Pulido-Bosch, A., Kemna, A., Nguyen, F., Tsourlos, P., 2007. Automated monitoring of coastal aquifers with electrical resistivity tomography. In: A. Pulido Bosch, J.A. López-Geta, G. Ramos González (Eds.), Coastal Aquifers: Challenges and Solutions, Instituto Geológico y Minero de España, Madrid, 333-342.

Ogilvy, R.D., , Meldrum, P.I., Kuras, O., Wilkinson, P.B., Chambers J.E., 2008. Advances in Geoelectric Imaging Technologies for the Measurement and Monitoring 
of Complex Earth Systems and Processes. Invited keynote paper in Proceedings $33^{\text {rd }}$ International Geological Congress, Oslo, Norway, 10-14 August 2008.

Oldenborger, G.A., Knoll, M.D., Routh, P.S., LaBrecque, D.J., 2007a. Time-lapse ERT monitoring of an injection/withdrawal experiment in a shallow unconfined aquifer. Geophysics 72, F177-F187.

Oldenborger, G.A., Partha, S.R., Knoll, M.D., 2007b. Model reliability for 3D electrical resistivity tomography: Application of the volume of investigation index to a time-lapse monitoring experiment. Geophysics 72, F167-F175.

Parasnis, D.S., 1988. Reciprocity theorems in geoelectric and geoelectromagnetic work. Geoexploration 25, 177-198.

Sandberg, S.K., Slater, L.D., Versteeg, R., 2002. An integrated geophysical investigation of the hydrogeology of an anisotropic unconfined aquifer. Journal of Hydrology 267, 227-243.

Shevnin, V., Delgado Rodríguez, O., Mousatov, A., Flores Hernández, D., Zegarra Martínez, H., Ryjov, A., 2006. Estimation of soil petrophysical parameters from resistivity data: Application to oil-contaminated site characterization. Geofísica Internacional 45, 179-193.

Singha, K., Gorelick, S.M., 2005. Saline tracer visualized with three-dimensional electrical resistivity tomography: Field-scale spatial moment analysis. Water Resources Research 41, W05023.

Singha, K., Gorelick, S.M., 2006. Hydrogeophysical tracking of three-dimensional tracer migration: The concept and application of apparent petrophysical relations. Water Resources Research 42, W06422.

Slater, L.D., Binley, A. Brown, D., 1997. Electrical imaging of fractures using ground-water salinity change. Groundwater 35, 436-442.

Slater, L., Binley, A.M., Daily, W., Johnson, R., 2000. Cross-hole electrical imaging of a controlled saline tracer injection. Journal of Applied Geophysics 44, 85-102.

Slater, L., Sandberg, S., 2000. Resistivity and induced polarization monitoring of salttransport under natural hydraulic gradients. Geophysics 65, 408-420.

Slater, L., Binley, A., 2003. Evaluation of permeable reactive barrier (PRB) integrity using electrical imaging methods. Geophysics 68, 911-921.

Thompson, R.D., 1998. Atmospheric Processes and Systems, Routledge, 194pp.

Vanderborght, J., Kemna, A., Hardelauf, H., Vereecken, H., 2005. Potential of electrical resistivity tomography to infer aquifer transport characteristics from tracer studies: A synthetic case study. Water Resources Research 41, W06013.

Wilkinson, P.B., Chambers, J.E., Meldrum, P.I., Ogilvy, R.D. \& Caunt, S., 2006. Optimization of array configurations and panel combinations for the detection and imaging of abandoned mineshafts using 3D cross-hole electrical resistivity tomography. Journal of Environmental and Engineering Geophysics 11, 213-221.

Wilkinson, P.B., Chambers, J.E., Lelliot, M., Wealthall, G.P., Ogilvy, R.D., 2008. Extreme sensitivity of crosshole electrical resistivity tomography measurements to geometric errors. Geophysical Journal International 173, 49-62. 
Zhou B., Dahlin T., 2003. Properties and effects of measurement errors on 2D resistivity imaging. Near Surface Geophysics 1, 105-117. 


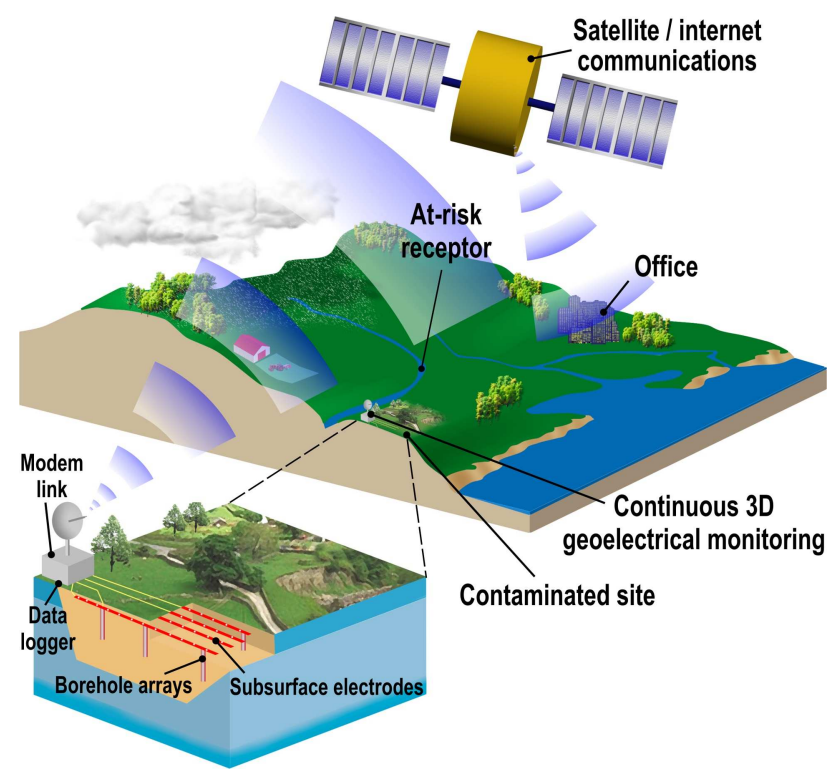

Figure 1. Schematic diagram of the CLARET concept. 

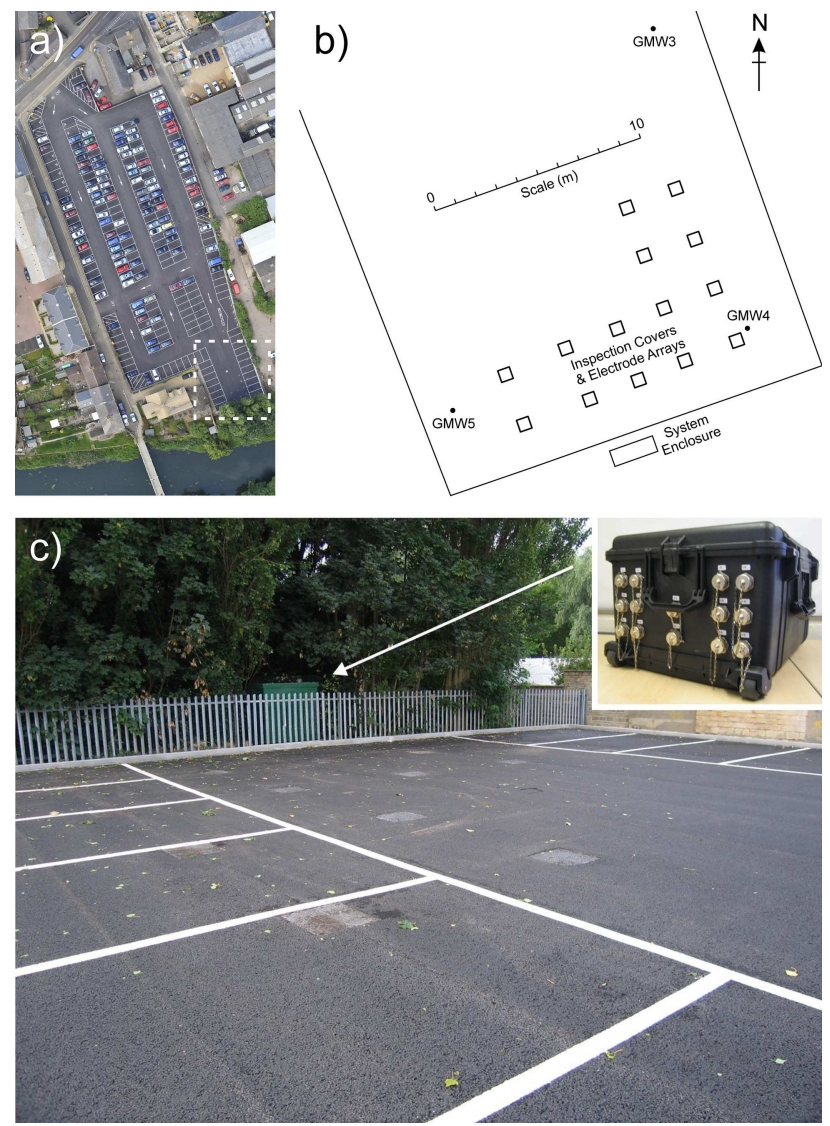

Figure 2. a) Aerial photograph of the Wharf Road test site, with monitoring region indicated by white dashed line. b) Scale diagram of monitoring region showing locations of borehole electrode arrays, groundwater monitoring wells (GMW3 - GMW5) and system enclosure. c) Site photo showing system enclosure, array inspection covers and ALERT resistivity monitoring system (inset). 

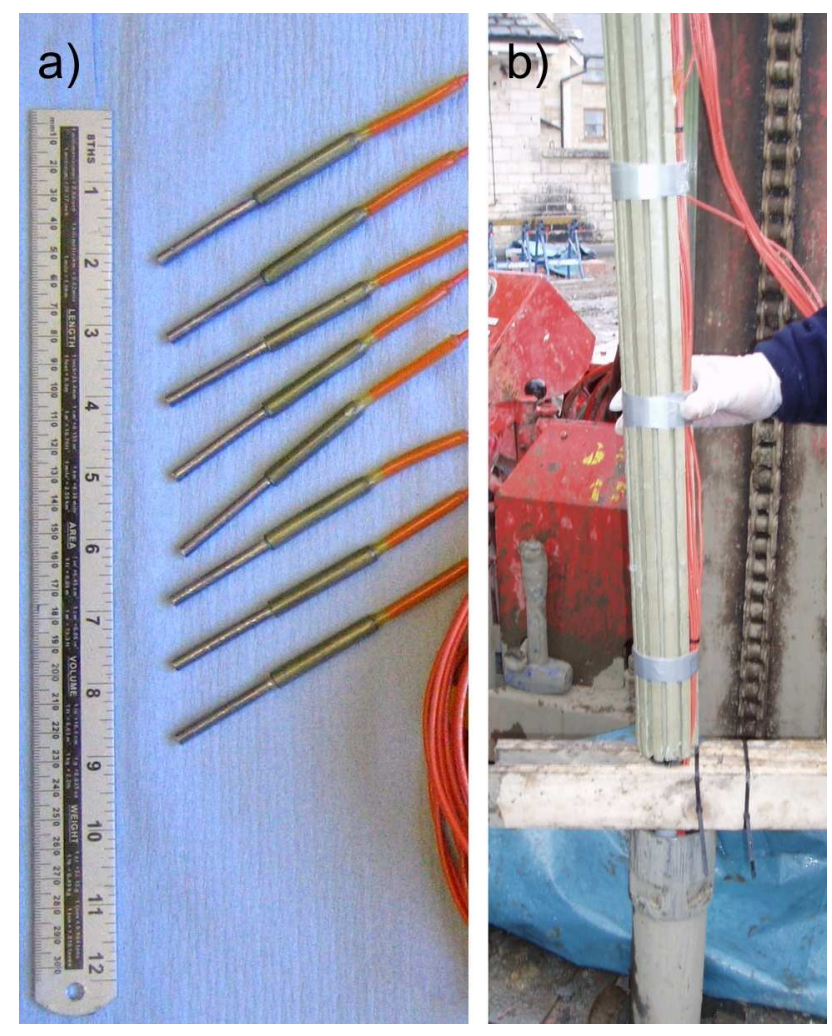

Figure 3. a) Phosphor bronze electrodes used in the borehole arrays. b) Installation of electrodes on bentonite collars before insertion into borehole. 


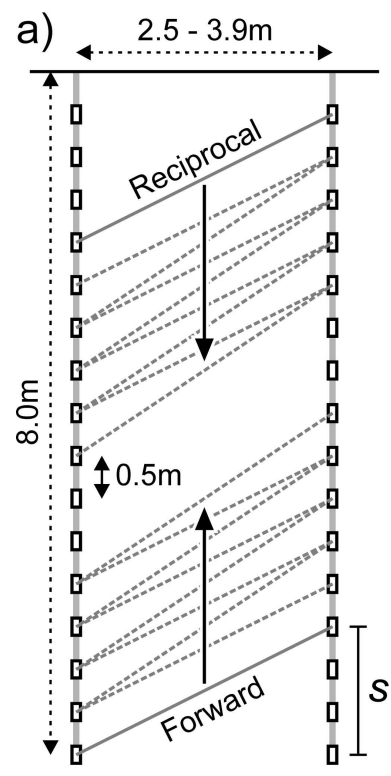

b)

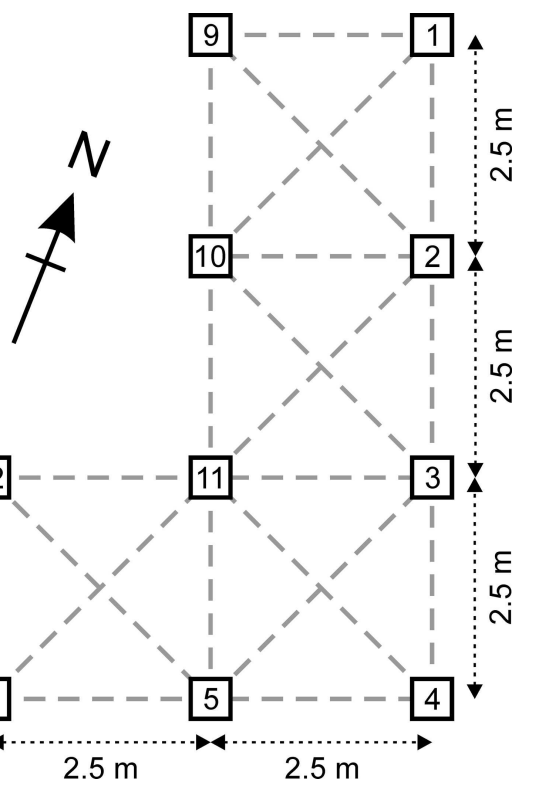

Figure 4. a) Schematic diagram of forward and reciprocal resistivity data collection for a vertical offset of $s$ electrode spacings. The solid and dotted lines indicate current and potential bipoles respectively. b) Borehole numbering and data collection panels (dashed lines). 


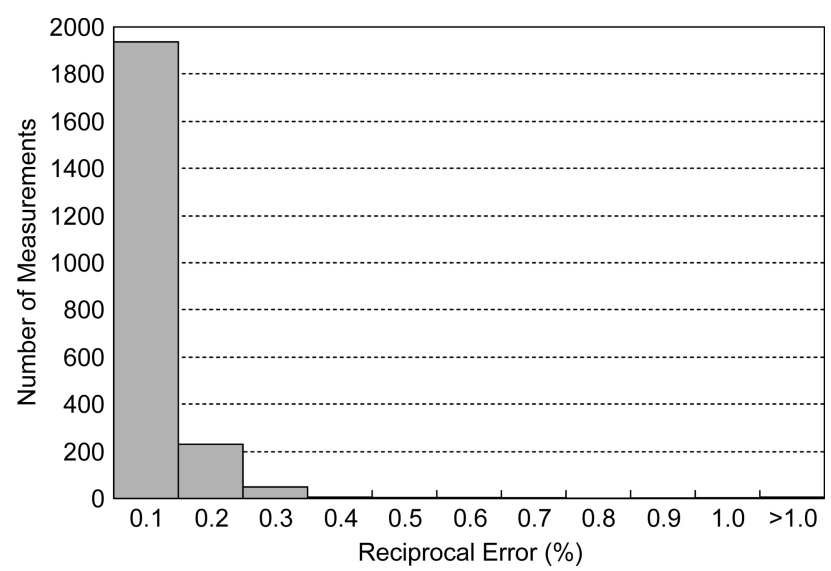

Figure 5. Distribution of reciprocal errors immediately prior to tracer test. 



Figure 6. $\quad$ a) \& b) 2D slices through the southern and eastern blocks respectively of a $3 \mathrm{D}$ resistivity image obtained from the full resolution data set. Electrode locations are shown by white rectangles. A lithological log from borehole 8 is shown on the right. c) \& d) Corresponding slices through the baseline image generated from the reduced resolution data set. The white circles show the electrodes used for the supplementary Wenner measurements. The resistivity scale for all images is shown on the right. 


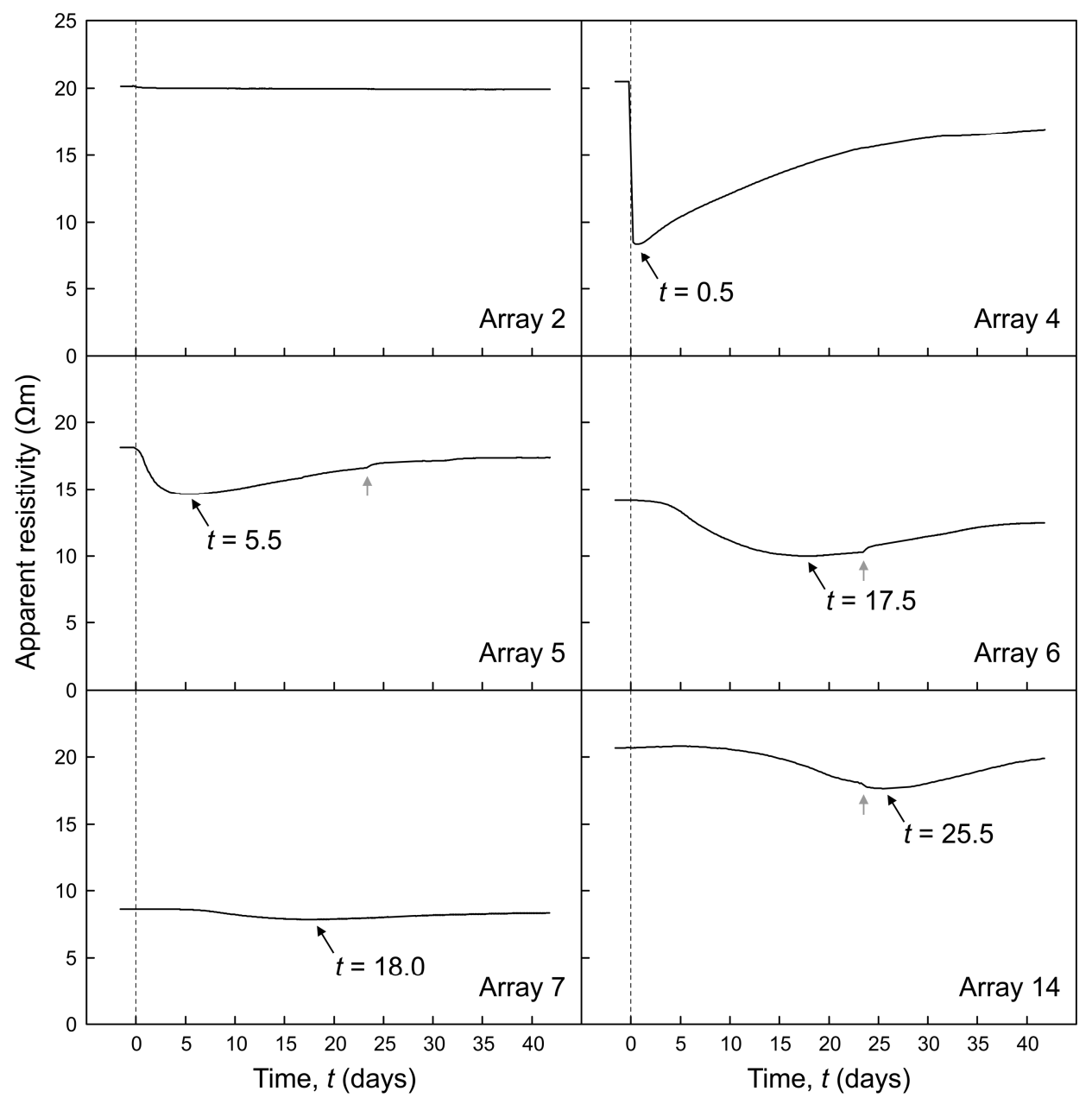

Figure 7. Wenner apparent resistivity breakthrough curves as a function of time $t$ after injection. The resistivity minima are indicated by large diagonal arrows. Small anomalous features affect three of the breakthrough curves (indicated by small vertical arrows). 

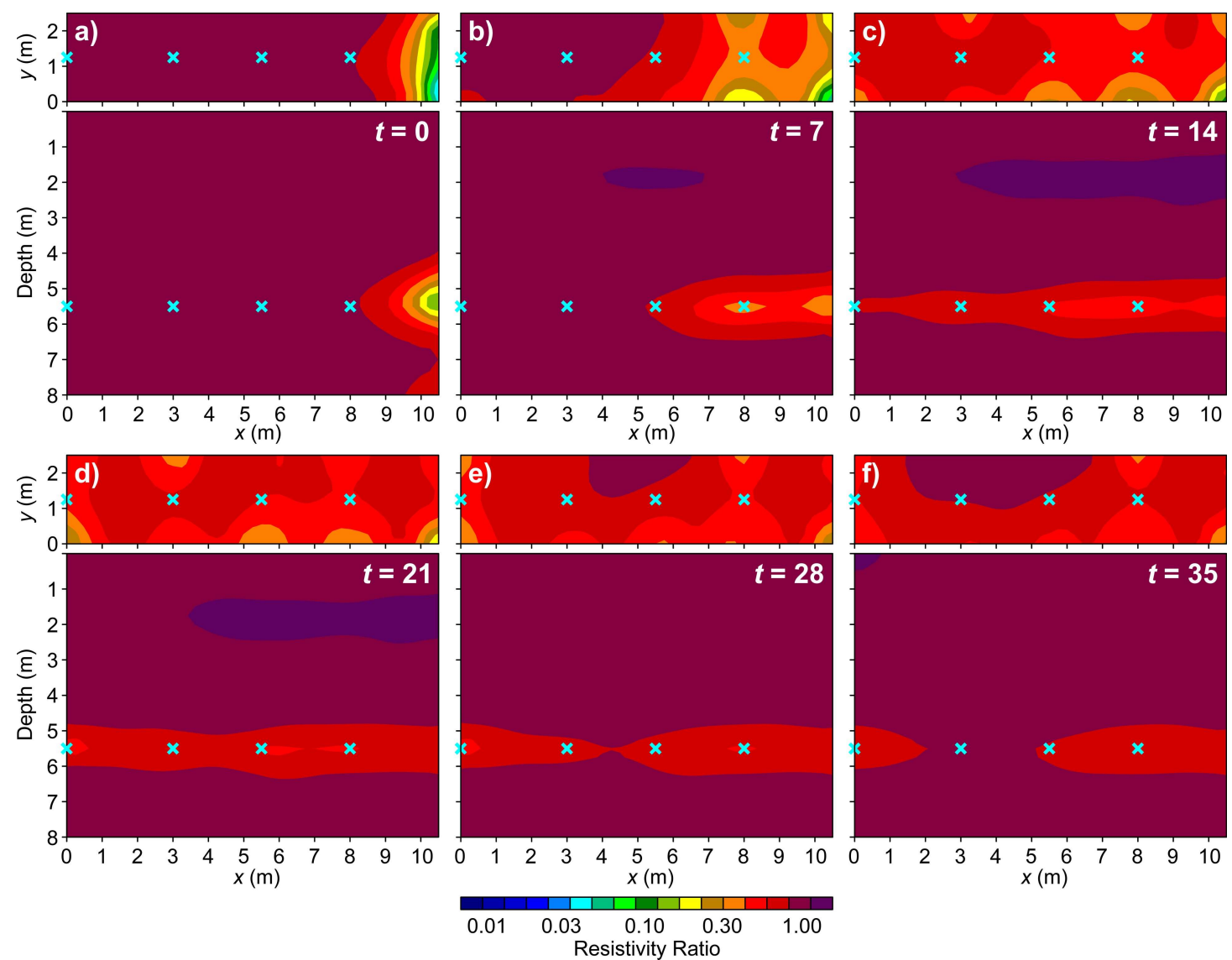

Figure 8. Horizontal (above) and vertical (below) slices through the southern blocks of the $3 \mathrm{D}$ resistivity monitoring images at time $t$ days after injection. The resistivity is shown normalised to the baseline image in Fig. 6c. Light blue crosses indicate the locations of the model cells used to estimate tracer breakthrough times from the resistivity images. 